\title{
NRAS NM_002524.4:C.38G>T
}

National Cancer Institute

\section{Source}

National Cancer Institute. NRAS NM 002524.4:C.38G>T. NCI Thesaurus. Code C155676.

A nucleotide substitution at position 38 of the coding sequence of the NRAS gene where guanine has been mutated to thymine. 